\title{
Faktor Predisposisi Bidan dalam Pelaksanaan Program Stimulasi, Deteksi Dini dan Intervensi Tumbuh Kembang (SDIDTK)
}

\author{
Dhea Nevira Khairunnisa ${ }^{1}$, Dini Saraswati Handayani², Sefita Aryuti Nirmala ${ }^{2}$, \\ Sri Astuti², Tina Dewi Judistiani ${ }^{2}$ \\ ${ }^{1}$ Fakultas Kedokteran Universitas Padjadjaran \\ ${ }^{2}$ Departemen Ilmu Kesehatan Masyarakat, Fakultas Kedokteran Universitas Padjadjaran
}

\begin{abstract}
Abstrak
Pembinaan tumbuh kembang anak secara komprehensif dan berkualitas diselenggarakan melalui kegiatan Stimulasi, Deteksi dan Intervensi Dini Tumbuh Kembang (SDIDTK). Program SDIDTK adalah program pokok Puskesmas DTP Kota Bandung yang dilaksanakan oleh tenaga kesehatan khususnya oleh bidan. Penelitian ini bertujuan untuk mengetahui faktor predisposisi bidan dalam pelaksanaan program SDIDTK. Metode penelitian yang digunakan adalah metode deskriptif dengan pendekatan cross sectional. Sampel yang digunakan adalah seluruh bidan yang bekerja di Puskesmas DTP Kota Bandung, berjumlah 75 bidan. Data yang digunakan adalah data primer diperoleh dari kuesioner yang diberikan kepada bidan. Penelitian ini dilaksanakan pada bulan Juli - Agustus 2016. Berdasarkan hasil penelitian diperoleh bidan berumur 26-30 tahun 37 orang (49,3\%), berpendidikan D3 66 orang $(88,0 \%)$, lama bekerja $>5$ tahun 37 orang $(49,3 \%)$, pernah pelatihan 15 orang $(20,0 \%)$ dan lama pelatihan $<1$ tahun, $1-2$ tahun, $>3$ tahun masing-masing 5 orang $(6,7 \%)$. Gambaran bidan yang memiliki pengetahuan cukup 39 orang $(52,0 \%)$ dan memiliki sikap positif 39 orang $(52,0 \%)$. Simpulan dari penelitian ini adalah pengetahuan dan sikap bidan yang merupakan faktor predisposisi dalam pelaksanaan program SDIDTK dapat dikatakan masih dalam kategori cukup. Pelatihan SDIDTK, seminar atau workshop mengenai pentingnya pemantauan tumbuh kembang anak sangat disarankan dengan harapan dapat meningkatkan pengetahuan bidan mengenai SDIDTK.
\end{abstract}

Kata kunci : Bidan, Faktor Predisposisi, SDIDTK

\section{Predisposing Factors of Midwife Towards Stimulations, Detection, and Growth Early Intervention (SDIDTK) Program}

\begin{abstract}
Supervision of the comprehensive and qualified children growth has been conducted through stimulation, detection, and growth early intervention (SDIDTK). SDIDTK program has already become main program in Puskesmas DTP in Bandung and become health care provider's job especially for midwives. The objective of this research is to figure out the predisposing factors of midwife towards stimulation, detection, and growth early intervention (SDIDTK) program. This research employed descriptive method of cross sectional approach. 75 midwives who work in Puskesmas DTP in Bandung were involved as the sample. In addition, the main data was collected from the questionnaire results which was spread to all midwives. This research was conducted on July - August of 2016. Based on the research known there are 37 respondents who are in between age 26-30 years old (49,3\%). There are 66 midwives who took D3 education (88,0\%), 37 midwives with working experiences $>5$ years (49,3\%), 15 midwives who have had training (20,0\%), and 5 midwives for each training period, $<1$ year, 1-2 years, $>3$ years $(6.7 \%)$ and there are 39 midwives who have enough knowledge $(52,0 \%)$ and 39 midwives who have positiive attitude (52,0\%). With regard to the findings, knowledge and attitude of midwives are predisposing factors which is affecting SDIDTK program and the knowledge and attitude of midwives towards SDIDTK program are in enough category. SDIDTK training, colloqium or workshop about the importance of child growth and development monitoring for midwives are highly recommended for increasing midwives 'knowledge about SDIDTK.
\end{abstract}

Keyword : Midwife, Predisposing Factor, SDIDTK

Korespondensi:

Dhea Nevira Khairunnisa

Fakultas Kedokteran Universitas Padjadjaran

Jl. Bandung - Sumedang KM. 21 Jatinangor

Mobile : 085624450827

Email :dheanvr@gmail.com 


\section{Pendahuluan}

Tumbuh kembang merupakan proses yang berkesinambungan yang terjadi sejak konsepsi dan terus berlangsung sampai dewasa. Perkembangan pada masa golden age adalah kunci untuk kehidupan yang produktif untuk anak dan juga untuk peningkatan bangsa. Bukti ilmiah menyatakan bahwa jika otak tidak menerima stimulasi yang tepat selama masa kritis ini, akan sangat sulit bagi otak untuk menghubungkan kembali sinaps-sinapsnya. Penelitian telah membuktikan bahwa setengah dari potensi intelegensi seseorang berkembang pada usia 4 tahun dan intervensi pada masa golden age dapat membuat efek berkelanjutan pada kapasitas intelektual, personalitas, dan sikap sosialnya. ${ }^{1,2}$

Balita adalah calon generasi penerus bangsa yang sedang berada dalam masa golden age, maka dari itu kualitas tumbuh kembang balita di Indonesia perlu mendapat perhatian serius yaitu mendapat gizi yang baik, stimulasi yang memadai serta terjangkau oleh pelayanan kesehatan berkualitas termasuk deteksi dan intervensi dini penyimpangan tumbuh kembang. Pembinaan tumbuh kembang anak secara komprehensif dan berkualitas yang diselenggarakan melalui kegiatan Stimulasi, Deteksi dan Intervensi Dini Tumbuh Kembang (SDIDTK). Program Stimulasi, Deteksi dan Intervensi Dini Tumbuh Kembang (SDIDTK) merupakan revisi dari program Deteksi Dini Tumbuh Kembang (DDTK) yang telah dilakukan sejak tahun 1988-1997 dan termasuk salah satu program pokok Puskesmas. Kegiatan ini dilakukan secara menyeluruh dan terkoordinasi diselenggarakan dalam bentuk kemitraan antara keluarga (orang tua, pengasuh anak dan anggota keluarga lainnya), masyarakat (kader, organisasi profesi, lembaga swadaya masyarakat) dengan tenaga profesional. ${ }^{3}$

Di Nigeria, Lembar Pemantauan Pertumbuhan adalah media skrining yang digunakan untuk mendiagnosa gangguan nutrisi, sistem kronik dan penyakit endokrin secara dini. Telah disarankan bahwa penggunaan Lembar Pemantauan Pertumbuhan memiliki potensi yang akan berdampak signifikan terhadap kematian anak. Berdasarkan penelitian yang dilakukan oleh Gunther Fink ditemukan bahwa anak-anak yang secara konsisten berada di bawah batas stunting dari usia $8-15$ tahun mengalami penurunan nilai sebanyak 0,7 poin saat usia mereka mencapai 15 tahun. Maka dari itu pemantauan pertumbuhan dan perkembangan yang berkelanjutan pada masa kanak-kanak dan remaja awal menjadi sangat penting untuk membantu mereka mencapai potensi perkembangan diri yang maksimal. ${ }^{4,5}$

Hasil penelitian yang dilakukan oleh Feti
Kumala Dewi di Puskesmas Teluk Purwokerto tahun 2013 mengenai efektifitas SDIDTK terhadap peningkatan angka penemuan dini gangguan tumbuh kembang pada anak usia balita ditemukan perbedaan yang bermakna mengenai angka penemuan gangguan tumbuh kembang anak yang diukur menggunakan SDIDTK dengan anak yang diukur menggunakan KMS. SDIDTK lebih efektif terhadap penemuan dini gangguan pertumbuhan dan perkembangan anak usia balita. $^{6}$

Hasil penelitian yang dilakukan oleh Hanik Machfudloh di Puskesmas Kabupaten Sidoarjo pada tahun 2011 mengenai faktorfaktor yang mempengaruhi kinerja bidan dalam pelaksanaan SDIDTK balita dan anak prasekolah didapatkan bahwa sebagian besar $(59,7 \%)$ kinerja bidan dalam pelaksanaan SDIDTK masih kurang, hal ini berkaitan dengan kurangnya kelengkapan peralatan $(54,5 \%)$, kurangnya pengetahuan $(62,3 \%)$ dan sikap bidan $(57,1 \%)$ terhadap pelaksanaan SDIDTK. ${ }^{7}$

Kinerja bidan yang kurang daam pelaksanaan SDIDTK tentunya dipengaruhi oleh perilaku bidan selaku tenaga kesehatan. Perilaku itu sendiri ditentukan atau terbentuk dari 3 faktor yaitu faktor predisposisi (predisposing factor) yang mencakup pengetahuan dan sikap, faktor pemungkin (enabling factor) yang mencakup lingkungan fisik, tersedia atau tidak tersedianya sarana prasarana, faktor penguat (reinforcing factor) yang merupakan faktor penguat bagi seseorang untuk mengubah perilaku seperti tokoh masyarakat, undang-undang, peraturan-peraturan dan surat keputusan. ${ }^{8}$

Berdasarkan hasil studi pendahuluan yang telah dilakukan dalam bentuk wawancara terhadap penanggung jawab Program SDIDTK di 5 Puskesmas DTP Kota Bandung yaitu Puskesmas Ibrahim Adjie, Puskesmas Padasuka, Puskesmas Puter, Puskesmas Garuda dan Puskesmas Pagarsih pada bulan November tahun 2015 didapatkan data jumlah bidan di masing-masing Puskesmas adalah 16 bidan di Puskesmas Ibrahim Adjie, 18 bidan di Puskesmas Padasuka, 13 bidan di Puskesmas Puter, 16 bidan di Puskesmas Garuda, dan 14 bidan di Puskesmas Pagarsih, serta ditemukan bahwa cakupan SDIDTK yang telah dilaksanakan di semua Puskesmas masih di bawah target yaitu sekitar 70-80\%, sedangkan target yang diharapkan adalah $90 \%$. Hal ini dikarenakan SDM yang tidak memadai sehingga tidak cukup waktu untuk melakukan SDIDTK. Rata-rata di semua Puskesmas terdapat 2 sampai 3 bidan yang telah mengikuti pelatihan SDIDTK.

Berdasarkan hal di atas maka peneliti tertarik untuk melakukan penelitian tentang "Faktor Predisposisi Bidan dalam Pelaksanaan Stimulasi, 
Deteksi dan Intervensi Dini Tumbuh Kembang (SDIDTK)", sehingga dapat diketahui kendala pencapaian target SDIDTK di Puskesmas DTP Kota Bandung yang bersumber pada masalah tenaga kesehatan bidan dan tindakan intervensi dapat dilakukan sedini mungkin dan anak dapat tumbuh dan berkembang dengan optimal sesuai usianya.

\section{Metode}

Penelitian ini menggunakan metode deskriptif dengan pendekatan secara cross sectional dengan tujuan untuk mengetahui faktor predisposisi bidan dalam pelaksanaan stimulasi, deteksi dan intervensi dini tumbuh kembang (SDIDTK). Data yang digunakan merupakan data primer yang diperoleh dari kuesioner yang dibagikan. Penelitian ini dilaksanakan pada tanggal 28 Juli1 Agustus 2016. Populasi dalam penelitian ini adalah seluruh Bidan yang bekerja di Puskesmas
DTP Kota Bandung yang sudah menjalankan program SDIDTK sebanyak 75 orang, dengan sebaran 16 bidan di Puskesmas Ibrahim Adjie, 18 bidan di Puskesmas Padasuka, 13 bidan di Puskesmas Puter, 16 bidan di Puskesmas Garuda dan 12 bidan di Puskesmas Pagarsih. Subjek penelitian dalam penelitian ini adalah semua Bidan yang bekerja di Puskesmas DTP Kota Bandung.

Kriteria inklusi adalah bidan yang bekerja di 5 Puskesmas DTP Kota Bandung yang sudah menjalankan program SDIDTK yaitu Puskesmas Ibrahim Adjie, Puskesmas Padasuka, Puskesmas Puter, Puskesmas Pagarsih dan Puskesmas Garuda dan bersedia untuk diteliti dan mengisi lembar kuesioner. Sedangkan kriteria eksklusi adalah bidan yang sedang mengambil cuti bekerja.

Penelitian ini telah mendapatkan persetujuan dari Komite Etik Penelitian Kesehatan Fakultas Kedokteran Universitas Padjadjaran dengan nomor ethical clearance 666/UN6.C1.3.2/KEPK/ $\mathrm{PN} / 2016$.

Hasil

Tabel 1 Gambaran Karakteristik Bidan di Puskesmas DTP Kota Bandung

\begin{tabular}{lcc}
\hline \multicolumn{1}{c}{ Karakteristik } & Frekuensi (f) & Persentase (\%) \\
\hline Umur & 11 & 14.7 \\
$21-25$ tahun & 37 & 49.3 \\
$26-30$ tahun & 27 & 36.0 \\
$\quad>30$ tahun & & \\
Pendidikan Terakhir & 0 & 0.0 \\
D1 & 66 & 88.0 \\
D3 & 9 & 12.0 \\
D4/S1 & 0 & 0.0 \\
S2 & & \\
Lama Bekerja & 2 & 2.7 \\
$<1$ tahun & 36 & 48.0 \\
1-5 tahun & 37 & 49.3 \\
$>5$ tahun & & \\
Pelatihan SDIDTK & 15 & 20.0 \\
Pernah & 60 & 80.0 \\
Belum Pernah & & \\
Lama Pelatihan & 5 & 6.7 \\
$<1$ tahun & 5 & 6.7 \\
1-2 tahun & 5 & 6.7 \\
$>3$ tahun & 60 & 80.0 \\
Tidak menjawab & &
\end{tabular}


Tabel 2 Gambaran Pengetahuan Bidan tentang SDIDTK

\begin{tabular}{lcc}
\hline Pengetahuan & Frekuensi (f) & $\begin{array}{c}\text { Persentase } \\
(\mathbf{\%})\end{array}$ \\
\hline Baik & 17 & 22.7 \\
Cukup & 39 & 52.0 \\
Kurang & 19 & 25.3 \\
$\quad$ Total & $\mathbf{7 5}$ & $\mathbf{1 0 0}$ \\
\hline
\end{tabular}

Tabel 3 Gambaran Sikap Bidan dalam Pelaksanaan SDIDTK

\begin{tabular}{lcc}
\hline \multicolumn{1}{c}{ Sikap } & F & \% \\
\hline Positif & 39 & 52.0 \\
Negatif & 36 & 48.0 \\
Total & $\mathbf{7 5}$ & $\mathbf{1 0 0}$ \\
\hline
\end{tabular}

Berdasarkan tabel 1 dapat diketahui bahwa responden yang berumur 26-30 tahun sebanyak 37 orang $(49,3 \%)$. Bidan yang berpendidikan D3 sebanyak 66 orang $(88,0 \%)$, lama bekerja $>$ 5 tahun sebanyak 37 orang $(49,3 \%)$, bidan yang pernah pelatihan sebanyak 15 orang $(20,0 \%)$ dan lama pelatihan $<1$ tahun, $1-2$ tahun dan $>3$ tahun masing-masing 5 orang $(6.7 \%)$.

Berdasarkan tabel 2 dapat diketahui bahwa bidan yang memiliki pengetahuan yang cukup yaitu 39 orang $(52,0 \%)$.

Berdasarkan tabel 3 di atas dapat diketahui bahwa bidan yang memiliki sikap yang positif yaitu 39 orang $(52,0 \%)$.

\section{Pembahasan}

Data yang diperoleh dari segi umur dapat diketahui bahwa bidan di Puskesmas DTP Kota Bandung lebih banyak pada kelompok usia 26-30 tahun dengan persentase 49,3\%. Kelompok usia 26-30 tahun berada pada masa dewasa awal yang salah satunya memiliki tugas perkembangan untuk mulai bekerja dan terlibat dalam hubungan masyarakat dan masih memiliki fisik yang kuat untuk mengelola satu wilayah kerja Puskesmas.

Data yang diperoleh dari segi pendidikan terakhir menunjukkan bahwa pendidikan terakhir sebagian besar bidan Puskesmas DTP Kota Bandung adalah D3 yaitu sebesar $88,0 \%$. Pendidikan dapat berpengaruh pada pengetahuan seseorang. Pendidikan dapat memperluas wawasan atau pengetahuan seorang bidan. Secara umum bidan yang berpendidikan lebih tinggi akan mempunyai pengetahuan yang lebih luas dibandingkan dengan bidan yang tingkat pendidikannya lebih rendah. ${ }^{8}$

Data yang diperoleh dari segi lamanya bekerja menunjukkan bahwa sebagian besar bidan Puskesmas DTP Kota Bandung sebanyak 49,3\% telah bekerja lebih dari 5 tahun di masingmasing Puskesmas. Pengetahuan seseorang dapat dipengaruhi oleh pengalaman. Pengalaman dapat diperoleh dari pengalaman sendiri atau orang lain. Pengalaman yang sudah diperoleh dapat memperluas pengetahuan seorang bidan. Lamanya seorang individu bekerja di suatu tempat atau organisasi dapat mempengaruhi tingkat pengetahuannya. Lamanya seorang individu bekerja dipengaruhi oleh prestasi kerja yang telah dicapai. Penilaian prestasi kerja mencakup kuantitas/jumlah yang diselesaikan, kualitas/ mutu yang dihasilkan, dan ketepatan waktu kerja/ sesuai tidaknya dengan waktu yang direncanakan.

Data yang diperoleh dari segi pelatihan SDIDTK menunjukkan bahwa sebagian besar bidan Puskesmas DTP Kota Bandung sebanyak $80 \%$ belum pernah mengkuti pelatihan SDIDTK. Hal ini sesuai dengan hasil studi pendahuluan yang telah dilakukan, bahwa di masing-masing Puskesmas hanya 2-3 bidan yang telah melakukan pelatihan SDIDTK dan pelatihan itupun dibiayai oleh pemerintah sehingga setiap Puskesmas dimintai perwakilan untuk mengikuti pelatihan.

Hasil penelitian yang dilakukan oleh Nadya pada tahun 2015 menunjukkan bahwa pelatihan SDIDTK mampu meningkatkan pengetahuan. Bidan dalam melakukan pemantauan tumbuh kembang anak dapat terlihat perbedaan yang bermakna dalam pengetahuan dan keterampilan bidan yang telah mengikuti pelatihan SDIDTK dan bidan yang belum pernah mengikuti pelatihan SDIDTK. ${ }^{9}$

Data yang diperoleh dari segi pengetahuan bidan mengenai SDIDTK sebagian besar bidan memiliki pengetahuan yang cukup, yakni sebesar 52,0\%. Setelah dilakukan analisis soal, bidan banyak menjawab salah di materi mengenai Tes Daya Lihat. Saat melakukan studi pendahuluan kepada penanggung jawab program SDIDTKdi masing-masing Puskesmas mengenai pengetahuan bidan tentang SDIDTK sebagian besar menjawab bahwa bidan-bidan Puskesmas berpengetahuan cukup karena masih banyak bidan yang belum mengikuti pelatihan SDIDTK dan mereka hanya melaksanakan SDIDTK sesuai dengan apa yang mereka pelajari di bangku kuliah dan sesuai dengan pedoman saat melakukan SDIDTK di Puskesmas. Hal ini sesuai dengan yang dijelaskan oleh Notoatmodjo, pengetahuan merupakan hasil tahu, dan hal ini terjadi setelah orang melakukan penginderaan terhadap suatu objek tertentu.

Pengetahuan seseorang dipengaruhi oleh beberapa faktor seperti umur, tingkat pendidikan dan pengalaman. Makin tua umur seseorang maka 
proses perkembangan mentalnya bertambah baik, pengetahuannya pun akan semakin luas. Pendidikan dapat memperluas wawasan atau pengetahuan seorang bidan. Secara umum bidan yang berpendidikan lebih tinggi akan mempunyai pengetahuan yang lebih luas dibandingkan dengan bidan yang tingkat pendidikannya lebih rendah. Pengalaman seseorang dapat dikaitkan dengan lamanya bekerja. Pengalaman yang sudah diperoleh dapat memperluas pengetahuan seorang bidan. Tingkat pengetahuan dalam domain kognitif mempunyai 6 tingkatan yaitu tahu, memahami, aplikasi, analisis, sintesis dan evaluasi. Jadi seseorang yang tahu tentang suatu hal akan dia aplikasikan dalam kehidupan seharihari. Pengetahuan bidan sangat berpengaruh pada kinerja yang dilaksanakan. Semua asuhan yang bidan berikan kepada klien nya berdasar pada pengetahuan yang dimiliki. ${ }^{8}$

Penelitian ini sejalan dengan penelitian yang dilakukan oleh Bhardwaj pada tahun 2015 mengenai Assesment of Growth Activities under Integrated Child Development Services di Nigeria bahwa sebesar $54,4 \%$ pekerja memiliki pengetahuan yang rendah mengenai pemantauan pertumbuhan. Rendahnya pengetahuan pekerja berdampak pada kualitas pemeriksaan yang diberikan, hanya $20 \%$ pekerja yang melakukan teknik pemeriksaan yang tepat. Hal tersebut dapat berdampak cukup besar pada hasil pemeriksaan tumbuh kembang anak. ${ }^{10}$

Data yang diperoleh dari segi sikap bidan terhadap pelaksanaan SDIDTK sebagian besar bidan memiliki sikap positif yaitu 52,0\%. Sikap bukanlah bawaan seseorang sejak ia dilahirkan melainkan dibentuk sepanjang perkembangan orang itu dalam interaksi dengan objek-objek tertentu yang ada di lingkungannya. Sikap bidan yang positif didapat dari pengetahuan, pengalaman dan informasi yang mereka dapatkan dari berbagai sumber. Pengetahuan seseorang dipengaruhi oleh pendidikan, baik formal maupun informal. Sikap positif ini diwujudkan dalam perilaku atau respon yang positif dan sebaliknya jika sikap seseorang tersebut negatif maka akan muncul sebuah perilaku negatif pula. ${ }^{11}$ Sikap bidan yang positif mengenai SDIDTK dapat diperoleh dari pengetahuan bidan akan pentingnya pemeriksaan tumbuh kembang yang didapat saat menempuh pendidikan kebidanan maupun dengan mengikuti pelatihan SDIDTK. Jika seorang bidan memiliki sikap yang positif mengenai SDIDTK maka diharapkan akan timbul respon yang positif berupa pelaksanaan SDIDTK. ${ }^{12}$

Penelitian ini sejalan dengan penelitian yang dilakukan oleh Adenike tentang peran tenaga kesehatan di pelayanan dasar mengenai pemantauan pertumbuhan anak, didapatkan hasil bahwa 98,4\% tenaga kesehatan di pelayanan dasar memiliki sikap yang positif mengenai pemantauan pertumbuhan anak dan setuju bahwa pemantauan pertumbuhan anak sangat efektif dalam meningkatkan status kesehatan anak. ${ }^{4}$

Berdasarkan hasil studi pendahuluan didapatkan bahwa pencapaian target SDIDTK belum mencapai target $90 \%$, hal ini bisa disebabkan oleh kinerja bidan yang kurang dalam pelaksanaan program SDIDTK. Hasil penelitian yang dilakukan oleh Hanik Machfudloh di Puskesmas Kabupaten Sidoarjo pada tahun 2011 mengenai faktor-faktor yang mempengaruhi kinerja bidan dalam pelaksanaan SDIDTK balita dan anak prasekolah didapatkan bahwa sebagian besar (59,7\%) kinerja bidan dalam pelaksanaan SDIDTK masih kurang, hal ini berkaitan dengan kurangnya kelengkapan peralatan $(54,5 \%)$, kurangnya pengetahuan $(62,3 \%)$ dan sikap bidan $(57,1 \%)$ terhadap pelaksanaan SDIDTK. ${ }^{7}$ Kinerja bidan yang kurang daam pelaksanaan SDIDTK tentunya dipengaruhi oleh perilaku bidan selaku tenaga kesehatan. Perilaku itu sendiri ditentukan atau terbentuk dari 3 faktor dan salah satu faktornya yaitu faktor predisposisi (predisposing factor) yang mencakup pengetahuan dan sikap. Hasil penelitian yang dilakukan oleh Abenike menyatakan bahwa meskipun tenaga kesehatan memiliki sikap positif dan kesadaran yang tinggi akan pentingnya pemantauan pertumbuhan anak, namun ditemukannya pengetahuan yang rendah mengenai prosedur dan interpretasi hasil pemeriksaan dapat mempengaruhi hasil pemeriksaan pertumbuhan anak itu sendiri yang nantinya akan berdampak pada intervensi pertumbuhan yang seharusnya diberikan. ${ }^{8,4}$

Dari data yang didapatkan pengetahuan bidan tentang SDIDTK paling banyak pada kategori cukup $(52,0 \%)$ dan sebagian besar sikap bidan positif $(52,0 \%)$ terhadap pelaksanaan SDIDTK. Kedua hal ini merupakan faktor predisposisi yang sangat berpengaruh pada proses pelaksanaan SDIDTK yang masih dibawah target. Jika presentase kedua faktor ini lebih ditingkatkan, serta didukung oleh peningkatan faktor-faktor lainnya (enabling and reinforcing factor), maka SDIDTK dapat dilaksanakan sebagaimana mestinya dan dapat mencapai target cakupan pelayanan SDIDTK. Keterbatasan dari penelitian ini adalah waktu yang singkat dalam pengambilan data. Saran yang diberikan adalah dilaksanakan penelitian lebih lanjut mengenai enabling factor dan reinforcing factor dalam pelaksanaan SDIDTK dan diadakannya pelatihan SDIDTK, seminar atau workshop mengenai pentingnya pemantauan tumbuh kembang anak atau SDIDTK untuk bidan secara merata agar meningkatkan pengetahuan bidan mengenai SDIDTK. 


\section{Daftar Pustaka}

1. Soetjiningsih, Ranuh IG. N. Gde. Tumbuh kembang anak. Jakarta: EGC. 2013.

2. United Nations Children's Fund, World Health Organization.

Early childhood development: the key to a full and productive life. New York: 2013.

3. Pedoman pelaksanaan stimulasi, deteksi dini dan intervensi dini tumbuh kembang anak ditingkat pelayanan kesehatan dasar. Jakarta: Kemenkes RI. 2011.

4. Adenike, Olugbenga-Bello, $\mathrm{O}$ AsekunOlarinmoye Esther. Primary health care workers 'role in monitoring children's growth and development in Nigeria, West Africa. Global Journal of Health Science. 2011 September 7, 2010;3(1):30-9.

5. Fink, Gunther, Rockers Peter C. Childhood growth, schooling, and cognitive development: further evidence from the Young Lives study. American Journal of Clinical Nutrition. 2014 May 7, 2014.

6. Dewi, Feti Kumala. Efektifitas SDIDTK terhadap peningkatan angka penemuan dini gangguan tumbuh kembang pada anak usia balita di Posyandu Teluk wilayah Puskesmas Purwokerto Selata. 2014.

7. Machfudloh, Hanik. Faktor-faktor yang mempengaruhi kinerja bidan dalam pelaksanaan stimulasi deteksi dan intervensi dini tumbuh kembang balita dan anak prasekolah di Puskesmas Kabupaten Sidoarjo. 2011.

8. Notoatmodjo, Soekidjo. Promosi kesehatan dan perilaku kesehatan. Jakarta: Rineka Cipta. 2012.

9. Devianty, Nadia. Hubungan antara pengetahuan dan pelatihan bidan dengan pelaksanaan SDIDTK di Wilayah UPT Puskesmas Sukarasa Kecamatan Sukasari Kota Bandung. 2015.

10. Bhardwaj, Pankaj, Sharma Sarthak, Raghav Pankaja, Kumar Dewesh. Assessment of growth monitoring activities under Integrated Child Development Services (ICDS) in western Rajasthan. International Journal of Medical Science and Public Health. 2015 October 11, 2015;5(7):1355-9.

11. Nisa, Shalihatun. Gambaran pengetahuan dan sikap bidan desa dalam pelaksanaan SDIDTK berdasarkan karakteristik di wilayah Kecamatan Jatinangor. 2016.

12. Arikunto, S. Prosedur penelitian suatu pendekatan praktek. Jakarta: Rineka Cipta. 2010 . 